\title{
Bridging the gap between selection decisions of facade systems at the early design phase: Issues, challenges and solutions
}

\author{
Mohamad Kassem ${ }^{\mathrm{a}, *}$ and Donald Mitchell ${ }^{\mathrm{b}}$ \\ ${ }^{a}$ Technology Futures Institute, Teesside University, Middleborough, UK \\ ${ }^{\mathrm{b}}$ Department of Architecture and Civil Engineering, Centre for Window Cladding Technology, \\ University of Bath, Bath, UK
}

\begin{abstract}
Building facade has a significant impact on the environmental and economic performance of buildings and projects. The specification of their elements at the early design phase depends on numerous technical, environmental and economic factors and involves several stakeholders. The procurement and delivery of the facade work package from the early design phase, through detailed design and manufacture, to installation is a process with several inherent risk factors due to the involved cost, technical and engineering complexities and its position on the critical path in all projects. This research investigates the process of selection and specification of building facade elements at the early design phases with the overarching aim of identifying the issues affecting specification decisions, their root causes and impact on projects. The research utilizes a mixed research approach which combines a retrospective case study and an industry survey as two research methods that build on each other. The findings suggest that the complexity of specification at the early design phases is exacerbated by factors such as the inadequate technical knowledge of stakeholders involved in the decision making process, the non-involvement of building facade consultants, the late involvement of specialist facade subcontractors, and in a few cases by some commercial exclusivity agreements that restricts specification decisions.
\end{abstract}

Keywords: Building facade, business process, curtain wall

\section{Introduction}

Building envelope (CWCT, 2003), facade (Pavitt \& Gibb, 2003) or building enclosures (Tran et al., 2014) are interchangeably used terminologies to denote the physical separator between the interior and the exterior environments of a building. The impact of building facade has become more important than ever in determining the operational and economic performance of construction projects. Indeed, the building facade accounts for anything between 15 and 25 per cent of the total construction costs and represents a substantial part of the technical and commercial risk on any given project

\footnotetext{
${ }^{*}$ Corresponding author: Mohamad Kassem, Technology Futures Institute, Teesside University, Middleborough, UK. Tel.: +44 (0) 1642 738300; Fax: +44 (0) 1642 342494; E-mail: m.kassem@tees.ac.uk. 
(Kragh, 2011a). Building facade is also an area of engineering by itself and its elements such as curtain wall systems are being used in various shapes and types, not only in new buildings but also during the renovation of existing structures (Efstathiades et a., 2007). This role is intensified by strict evolving energy performance standards and regulations (Kragh, 2011b). Procuring building facade is perceived as a process with many risks due to the numerous stakeholders, cost, technical and engineering requirements involved, and its position on the critical path in all projects. In addition, the broad range of commercial options available with varying economic, environmental and technical performances increase the challenges associated with the selection and delivery of building facade projects. Indeed, devising an optimal building facade solution is becoming increasingly difficult due to the growing number of building facade components and systems (Jin \& Overend, 2010). Research efforts analyzing decision making in design and construction processes are often concerned with analyzing issues affecting the performance of construction projects at industry-wide level as evidenced from the literature review presented later. As a result, there is limited research focused on analyzing specific design and engineering processes such as the selection of building facade elements at the early design phase. Hence, this research aims to investigate the process of selecting building facade elements at the early design phase, identifies the issues affecting accurate selection decisions and presents recommendations. In the subsequent sections, related research identifying causes of poor performance in the construction industry in general and current research to improve building facade in particular are first presented to understand both the gap and significance of the proposed research. Then, background information about the factors involved in the selection of building facade elements is illustrated to help the understanding of the complexity of selection decisions. Third, the research methodology, which consists of a retrospective case study and an industry survey, is explained to justify both the research design and research methods followed by a detailed presentation of results from both the case study and the survey.

\section{Literature review}

Studies investigating the issues that affect the performance of projects have proliferated over the last few years, especially within the construction sector. Much of these studies have focused on identifying factors that cause time, cost overruns and quality issues. The majority of these studies is focused at sector level (i.e. construction industry) and is based on quantitative survey approaches. The review of these studies can be classified in terms of 'domain', 'granularity' and 'approach' of investigation:

- Domain of investigation: represents the sector segment in which the research was conducted (e.g. building, civil, residential, etc.).

- Granularity of investigation: denotes the depth in the exploration of the issues researched structured into three levels namely, country or sector, project and single discipline or trade.

- Approach of investigation: refers to the research methods used in the investigation (e.g. case study, questionnaire, interviews).

A classification of a non-exhaustive list of studies according to these three fields is reported in Table 1. The results show that the majority of existing studies are focused at sector wide level and there is still lack of studies at building discipline or trade level. Table 2 reports the issues identified as main causes for poor performance in projects from the same studies classified in Table 1. Extensive 
Table 1

Classification of a non-exhaustive list of previous studies according to their domain, granularity and research approach

\begin{tabular}{|c|c|c|c|c|c|c|c|c|c|c|}
\hline & & 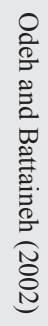 & 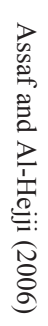 & 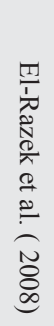 & 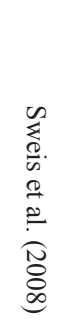 & 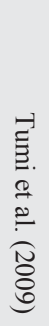 & 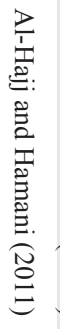 & 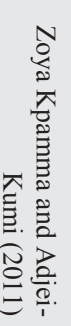 & 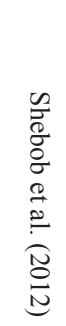 & 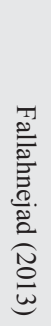 \\
\hline \multirow[t]{4}{*}{$\begin{array}{l}\text { Domain of } \\
\text { investigation }\end{array}$} & $\begin{array}{l}\text { Gas \& power } \\
\text { industry }\end{array}$ & & & & & & & & & - \\
\hline & $\begin{array}{l}\text { Building \& } \\
\text { Residential }\end{array}$ & & & - & - & & & - & & \\
\hline & Public sector & - & & & & & & & & \\
\hline & $\begin{array}{l}\text { Construction } \\
\text { (not specified) }\end{array}$ & - & - & & & - & - & & - & \\
\hline \multirow{3}{*}{$\begin{array}{l}\text { Granularity } \\
\text { of } \\
\text { investigation }\end{array}$} & Sector / Country & - & $\bullet$ & - & - & - & - & - & - & - \\
\hline & Project & & & & & & • & & & \\
\hline & $\begin{array}{l}\text { Single building } \\
\text { trade }\end{array}$ & \multicolumn{9}{|c|}{ Gap in existing research } \\
\hline \multirow[t]{3}{*}{$\begin{array}{l}\text { Approach of } \\
\text { investigation }\end{array}$} & Questionnaires & $\bullet$ & $\bullet$ & $\bullet$ & - & $\bullet$ & $\bullet$ & - & $\bullet$ & $\bullet$ \\
\hline & Interviews & & & & & & • & & & \\
\hline & Case study & \multicolumn{9}{|c|}{ Gap in existing research } \\
\hline
\end{tabular}

existing reviews in this domain have also reached similar conclusions. Sun and Meng (2009), in their effort to develop a taxonomy for change causes and effects in construction projects, reviewed 101 articles from the same source used in Table $1 .^{1}$

Much of the identified articles have either focused at wide industry scale using a quantitative survey-based approach. Although this research approach, focusing on industry and market level, is valuable in identifying the main areas of deficiencies in the industry that require improvement, it suffers two limitations. The first limitation lies in the nature of causes identified (see Table 2) which are often general statements of the areas where the actual root-causes of poor performance lie (Table 2). The second limitation is the lack of empirical evidence of the issues identified and their impact. From research design perspective, this approach could have unknown, remedial or biased population sampling and data collection methodologies (Succar \& Kassem, 2015).

As a result, there is a need for complementing the current research approach with a new methodology in which the granularity of investigation is increased from sector and market-level to a single building trade level, combined with case studies to provide the empirical demonstration and support.

One study, specific to the domain of building facades, was jointly funded by the Korean government and a large industrial conglomerate in South Korea (i.e. Daelim Industrial Co Ltd; Better Living Space,

\footnotetext{
${ }^{1}$ e.g. Journal of Construction Engineering and Management; International Journal of Project Management; Construction Management and Economics; Journal of Management in Engineering; and Engineering, Construction and Architectural Management.
} 
Table 2

Types of issues affecting industry and projects

\begin{tabular}{|c|c|}
\hline & \multirow{2}{*}{ Issues identified } \\
\hline & \\
\hline $\begin{array}{r}\text { Odeh, \& Battaineh } \\
(2002)\end{array}$ & $\begin{array}{l}\text { - Inadequate contractor experience } \\
\text { - Client interference } \\
\text { - Clients' financing }\end{array}$ \\
\hline $\begin{array}{r}\text { Assaf, \& Al-Hejji } \\
(2006)\end{array}$ & $\begin{array}{l}\text { - Shortage of labour } \\
\text { - Delays in clients' payments } \\
\text { - Type of project bidding }\end{array}$ \\
\hline El-Razek, et al. (2008) & $\begin{array}{l}\text { - Contractors' finance } \\
\text { - Delays in client payments } \\
\text { - Clients' design changes }\end{array}$ \\
\hline Sweis, et al. (2008) & $\begin{array}{l}\text { - Contractor poor planning } \\
\text { - Contractors' finance } \\
\text { - Clients' change orders }\end{array}$ \\
\hline Tumi, et al. (2009) & $\begin{array}{l}\text { - Improper planning } \\
\text { - Lack of effective communication } \\
\text { - Design errors }\end{array}$ \\
\hline $\begin{array}{r}\text { Al-Hajj, \& Hamani } \\
\text { (2011) }\end{array}$ & $\begin{array}{l}\text { - Lack of awareness } \\
\text { - Excessive off-cuts resulting from poor design } \\
\text { - Rework and variations }\end{array}$ \\
\hline $\begin{array}{r}\text { Zoya Kpamma, \& } \\
\text { Adjei-Kumi (2011) }\end{array}$ & $\begin{array}{l}\text { - Low recognition of sources of waste } \\
\text { - Little awareness of waste reduction tools } \\
\text { - Inadequate familiarity of the firms with lean thinking }\end{array}$ \\
\hline Shebob, et al., 2012 & $\begin{array}{l}\text { - Drawing approval delays } \\
\text { - Adverse weather conditions } \\
\text { - Delays to site handover to contractor }\end{array}$ \\
\hline Fallahnejad (2013) & $\begin{array}{l}\text { - Problems with importing materials } \\
\text { - Unrealistic contract durations } \\
\text { - Slow delivery of clients' materials }\end{array}$ \\
\hline
\end{tabular}

and Doalltech Co.) and aimed to improve the lifecycle of curtain wall through the integration of the supply chain through information management systems (Chin et al., 2004; Hwang et al., 2006). Factors such as the difficulty of involving the right people at the right time; lack of information sharing and communication; information loss due to the fragmentation of processes; redundancy and inaccuracy in information flow; long lead time between activities in the process, and reworks and errors due to missing and inaccurate information in the documentation (Chin et al., 2004; Hwang et al., 2006) were considered as issues affecting the performance of the curtain wall industry. However, neither a description of the identification process nor a statistical and empirical evidence of such issues were provided. Other related studies to building facade have focused on design methodologies to achieve specific technical performance such as sustainability and buildability (Singhaputtangkul et al., 2014; Mohsen \& Elaheh, 2012).

This paper aims to fill this identified gap while adopting a new research approach. Such an approach consists of increasing the granularity and scale of investigation by focusing on a specific building discipline or trade (i.e. building facade) while considering its interactions with other trades such 
as architectural and structural interactions. In addition, it combines the survey approach with a retrospective case study to provide empirical evidence of the issues and their impacts.

\section{The complexity of selection of building facade elements: The case of curtain wall}

A curtain wall is defined as a thin, usually aluminium framed wall, containing in-fills of glass, metal panels or thin stone in addition to glazed-in window and door openings (Vigener \& Brown, 2012). Curtain wall is classified according to the method of manufacture and installation as either stick systems or unit systems (Eastman et al., 2011).

A stick system consists of a framework of site assembled components which is used to support glass and infill panels (CWCT, 2000a). A unit or unitised system is a prefabricated wall which is transported to site as unitised frames, normally pre-glazed (CWCT, 2000a). The primary structural elements of curtain walls are mullions (vertical elements) and transoms (horizontal elements) (Fig. 1). Vertical mullion usually spans the full height of the cladding - in the case of stick systems - and they are connected to the horizontal transom using angle cleats, sleeves, spigots or proprietary brackets (CWCT, 1999). The framework of mullions and transoms supports infill panels, which may be glazing units or insulated panels. Mullions and transoms are usually made of extruded aluminium but may be made of steel in some cases (CWCT, 1999). A number of well established suppliers, mostly large and multinational companies, produce and commercialise numerous curtain wall systems. The commercial meaning of a curtain wall system is a collection of curtain wall products (mullions and transoms) having the same section shape but with different dimensions (length, width, height) in order to cover a range of performance required such as: different spans (distance between two mullions), maximum wind deflection, and different glass or infill weights.

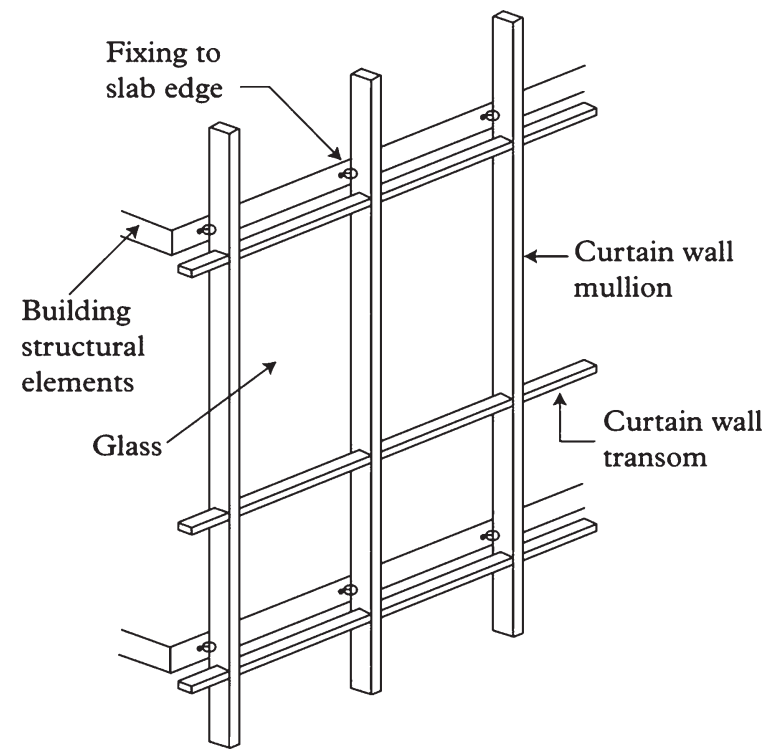

Fig. 1. Main elements of curtain wall. 
Table 3

Engineering and environmental parameters involved in curtain wall selection

\begin{tabular}{|c|c|}
\hline $\begin{array}{l}\text { Water } \\
\text { tightness }\end{array}$ & $\begin{array}{l}\text { Curtain wall systems have two different methods to deal with water tightness, namely: } \\
\text { face sealed systems and drained and ventilated systems. Face sealed systems have the } \\
\text { water penetration line at the front of the system. Drained systems allow a certain } \\
\text { amount of water to penetrate past the first weather seal gaskets, but a pressure } \\
\text { equalised chamber is formed in the system that causes any penetrating water to be } \\
\text { drained back to the outside via drainage holes positioned in the exterior face (CWCT, } \\
\text { 2000b). }\end{array}$ \\
\hline Air tightness & $\begin{array}{l}\text { Adequate air tightness of the curtain walling is required to prevent occupier } \\
\text { discomfort that may occur due to draughts and/or noise (CWCT, 2000b). The lack of } \\
\text { air tightness can result in air leakage leading to heat loss during winter and excessive } \\
\text { energy requirements during summer. }\end{array}$ \\
\hline $\begin{array}{l}\text { Thermal } \\
\text { Performance }\end{array}$ & $\begin{array}{l}\text { Curtain wall systems contribute to building energy efficiencies through their thermal } \\
\text { performance such as their conductance, which is a function of the frame material, } \\
\text { geometry and fabrication (Vigener \& Brown, 2012). }\end{array}$ \\
\hline $\begin{array}{l}\text { Acoustic } \\
\text { Performance }\end{array}$ & $\begin{array}{l}\text { The acoustic performance of curtain walls is mainly determined by their infill } \\
\text { materials. The acoustic performance can also be improved by making the construction } \\
\text { as airtight as possible and using sound attenuating glazing and panels (CWCT, 2003) }\end{array}$ \\
\hline $\begin{array}{l}\text { Movement } \\
\text { accommodation }\end{array}$ & $\begin{array}{l}\text { Curtain wall systems are required to accommodate the structural movement of the } \\
\text { building they are secured to. The capacity of accommodating building movement } \\
\text { depends on the shape and dimensions of the curtain wall section selected (CWCT, } \\
\text { 2007). }\end{array}$ \\
\hline Wind loading & $\begin{array}{l}\text { The ability of curtain wall systems to withstand wind loads depends on their shape } \\
\text { and the way they are attached to the structure at floor slab levels through brackets that } \\
\text { transfer the wind load to the structure. While transferring the wind loads to the } \\
\text { structure, the curtain walls are also subject to deflection and therefore, their shapes } \\
\text { and dimensions are crucial to insure that the maximum deflection is not exceeded } \\
(\mathrm{CWCT}, 2000 \mathrm{c}) \text {. }\end{array}$ \\
\hline Fire safety & $\begin{array}{l}\text { The installation of a curtain wall system influences the passage of fire and smoke. The } \\
\text { installation usually leaves gaps between floors horizontally and between party walls } \\
\text { vertically to allow the passage of fire and smoke. Many standard products (i.e. fire } \\
\text { break materials) are available and are specified by the amount of time they can } \\
\text { withstand the passage of fire and smoke (CWCT, 2011). }\end{array}$ \\
\hline Maintenance & $\begin{array}{l}\text { All facades require maintenance during the building operation phase (Vigener \& } \\
\text { Brown, 2012). The degree of maintenance and inspection depends on the facade type } \\
\text { and the intended design life. The early detection of defects can mitigate expensive } \\
\text { repairs or even replacement. Therefore, safe and easy access for conducting } \\
\text { maintenance operations and possible disruption to occupiers are factors that are } \\
\text { considered in the design and selection process. }\end{array}$ \\
\hline Buildability & $\begin{array}{l}\text { Ease, safety and access methods are all factors associated with buildability. For } \\
\text { example, the method of erection must be considered during the design stage by taking } \\
\text { into account accessibility and site logistics (HSE, 2007). Regulations issued by the } \\
\text { Construction Design and Management (HSE, 2007) dictate criteria that go beyond the } \\
\text { construction phase and stipulate that the facade must be accessible for replacement } \\
\text { and end of life dismantling of the structure. }\end{array}$ \\
\hline
\end{tabular}

The curtain walls and other building facade elements are a prerequisite in achieving occupant satisfaction, building efficiency and economic construction strategies. Their specification and selection is a challenging process due to the numerous architectural, engineering, economic and environmental parameters (Table 3 ) and stakeholders (i.e. architect, client, engineering consultants, vendors and specialist subcontractors) involved in the decision. 
The thresholds of these performance parameters may vary between different countries' national building codes. For example, the air leakage rate through a curtain wall for the United States market is limited to 0.3 litres $/ \mathrm{sec}^{*} \mathrm{~m}^{2}$ at $75 \mathrm{~Pa}$ air pressure difference. In Canada, the air leakage rate is limited to 0.1 litres $/ \mathrm{sec}^{*} \mathrm{~m}^{2}$ at $75 \mathrm{~Pa}$ air pressure difference (Quirouette, 2013).

\section{Research methodology}

This research aims to investigate the issues affecting the selection process of building facade elements such as curtain wall systems and the impact of selection decisions on projects. To achieve this aim, the research utilizes mixed research methods consisting of retrospective case study and an industry survey of stakeholders involved in selection decisions. This approach is a form of triangulation in which the weakness in each single method is compensated by the counter-balancing strengths of another (Amaratunga et al., 2002) and enables to elaborate or develop analysis, providing richer details (Rossman \& Wilson, 1991). The retrospective case study is used to confirm and introduce, by presenting empirical evidence, some of the issues affecting building facade projects and their impact on project performance. However, case studies are not generalizable to a sampling universe but instead directly confirm or disconfirm theory and hypotheses (Yin, 1994). As such, the retrospective case study approach is utilized in this research primarily to confirm the existence of issues in selection decisions and secondly to illustrate the impact of incorrect selection decisions. The case study is complemented with an industry survey followed by face to face and phone interviews with industry experts to identify and analyze the range of issues associated with the early selection of curtain wall systems. Following the retrospective case study, the business process for curtain wall selection adopted on the case study project is also mapped to show the deficiencies of current processes.

\section{Retrospective case study}

The case study is a multi-million dollar hotel located in London, UK. Curtain wall is the main element of the building facade with a commercial value just over eight million dollars. This project is representative of the research problem in terms of products (i.e. curtain wall systems) and stakeholders (i.e. client, contractor, and architect) involved. The project's data were obtained through 'retrospective story telling' through three interviews with the project manager responsible for the delivery of the building facade. The project manager works for the specialist facade subcontractor responsible for the detailed engineering design, manufacturing and installation of facade. The project manager collaboratively works with the architect, contractor, curtain wall vendors and other subcontractors to resolve every facade related issue on site and it is in his best interest that things go smoothly on site. Therefore, the storytelling by the project manager can be considered unbiased. The three interviews with the project manager respectively addressed three distinct areas: the original specification and issues encountered, the corrective actions, and the impact on the project. Only one part of the building facade, which is at the lower ground floor bar area, is used for this study. It should be noted however, that there were similar issues encountered in other areas of the build. The main contractor for the project was one of the largest contractors operating in the UK and worldwide, and the architects were of a major London-based architectural firm. A medium-sized company was employed as a specialist sub-contractor with design responsibility for the building envelope under contract to the main contractor. The curtain wall system used on the project was specified before the 
specialist sub-contractor was appointed and was supplied by one of the major three vendors who will be referred to in the remaining part of the paper as vendor $A$, vendor $B$ and vendor $C$, due to confidentiality of commercial information. The three vendors together have more than $70 \%$ of the UK market share valued at \$250 million in 2008 Companies House - a UK Government database where company accounts can be consulted - tax returns and are multinational companies operating worldwide. The selected curtain wall system was also specified, based on a commercial partnership between the main contractor and vendor $A$, in which the contractor is committed to use vendor's products on all projects. In addition, there were further constraints relating to aesthetic and architectural aspects imposed by the architect and other structural constraints. These factors will be discussed in more detail in the subsequent section of the case study.

\subsection{The design intent and issues phases}

The design intent and brief, received by the specialist subcontractor for the ground floor bar area from the architects, specified structurally glazed curtain wall screens with a span of 7.7 meters in height with mullion centers at 1.67 meters (Fig. 2). A mid transom split the screen at a height of 3.5 meters from the bottom transom and 3.45 meters to the top transom. The selected curtain wall system at the early specification phase was supplied by vendor $A$.

When the design brief and early specification was received by the specialist building facade subcontractor for the detailed engineering design stage, several issues were encountered:

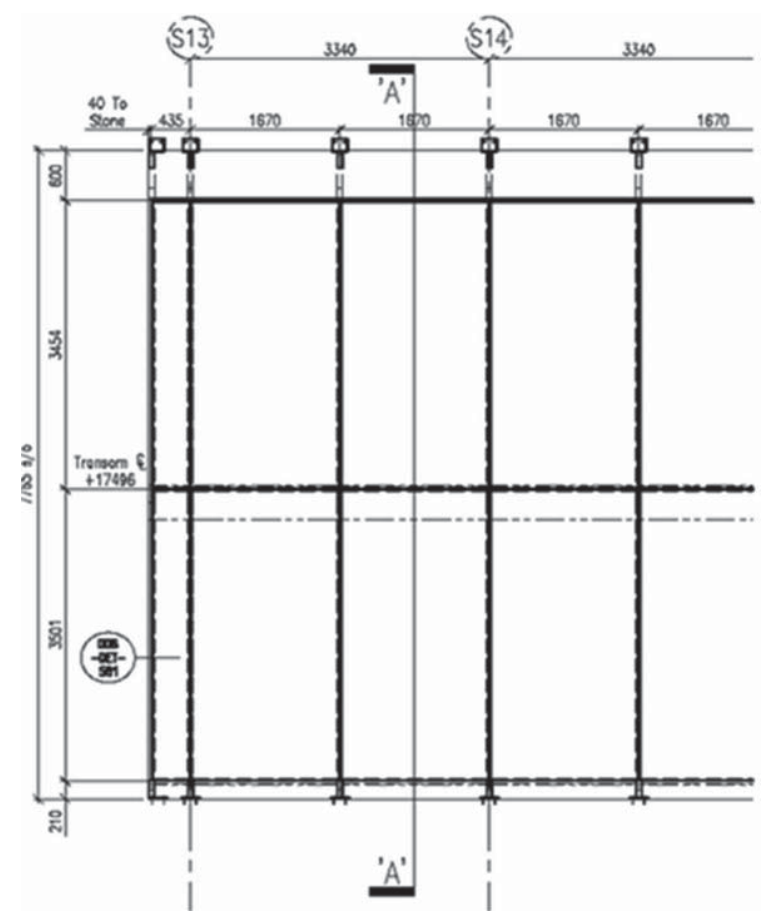

Fig. 2. Drawing of the curtain wall screen. 
- Deflection of the selected mullion exceeded the maximum deflection allowed: The selected mullion specifies a maximum deflection as the ratio between the length of the curtain wall screen and ' 300 ', which gives in this case a deflection of $25.7 \mathrm{~mm}$ (i.e. 7700/300) that exceeds $15 \mathrm{~mm}-$ the recommended maximum deflection by BS EN 13830:2003. Therefore, the product specified at the early design stage does not meet the structural requirement.

- Maximum glass weight supported: The maximum glass weight that the transoms of the selected system could support was 250 kilograms according to the specification of the vendor. The weight of the glass is usually calculated using the empirical formula that each msq of glass weighs 2.5 kilograms per $1 \mathrm{~mm}$ thickness. The thickness is a function of the barrier loads. In this case, the barrier loads dictated that the glass thickness required was $10 \mathrm{~mm}$ outer panes and $13.8 \mathrm{~mm}$ inner panes. The section size in this case is $5.84 \mathrm{msq}$ (i.e. $1.67 \mathrm{~m} \times 3.5 \mathrm{~m}$ ) and the glass weight is $347.5 \mathrm{kgs}$ (i.e. $5.84 \mathrm{~m}^{2} \times 2.5 \mathrm{kgs} \times 23.8 \mathrm{~mm}$ ), which exceeds 250 kilograms - the maximum glass weight that could be supported by the selected product.

- Mullions length available: The selected off-the-shelf curtain wall system is supplied by vendor A with mullions having a length of 6.5 meters only. Therefore, this system cannot satisfy the height to the top transom (i.e. $7.005 \mathrm{~m}$ ) required at the ground floor bar area of the build.

It is important to emphasize that the issues encountered were spotted at the construction stage during which any design change affects the overall project delivery time and cost, as is widely known in the literature. The subsequent section describes the systematic effort undertaken to explore options for rectifying the identified issues.

\subsection{Actions taken}

A number of actions were systematically undertaken to address each of the encountered issues while simultaneously considering commercial, structural and aesthetic constraints:

- Deflection issue: Sections with larger width supplied by the same vendor (i.e. vendor A) were examined as an alternative. A $65 \mathrm{~mm}$ wide box section was identified. However, structural analysis showed that this box size could not meet the required deflection even with the inclusion of steel inserts. Another alternative section, whose width was $15 \mathrm{~mm}$ larger than the width of the system initially specified, could be meeting the deflection requirement, but it required a joint in its length to satisfy the maximum length required. The architect involved rejected this solution, as no secondary steel was allowed to be used between the mullion span points. This would be visible and totally unacceptable to the architectural intent.

- Glass weight: The curtain wall system selected could not support the required glass weight. To overcome this issue, it was proposed to bolt the transom to the mullion's shear jointing blocks. The architects rejected this option as any face fixings on the curtain wall screen was not allowed. Then, an extra transom could be introduced to cut the glass size down and consequently bring the glass unit weight within acceptable limits. The architects rejected this solution also, as it would affect the initial design intent and would require planning re-approval. Therefore, it appeared that there were no solutions to this problem without the need to reconsider planning permissions.

- Mullions' length available: The mullions of the selected curtain wall off-the-shelf system were available in 6.5 meters lengths only. Vendor A was approached to enquire if a special length mullion could be produced. The vendor could not satisfy this requirement. An alternative was to introduce a spigot joint in the mullion at suitable points to achieve the lengths required. The 
architects rejected this option as a seamless mullion span was a key aesthetic requirement. Then, the technical department of the curtain wall's supplier (i.s. vendor A) was requested whether they could grant a concession for using the selected product with the exceeding glass weight. The supplier did not approve of this concession.

\subsection{Consequences}

The issues encountered were not resolved after exhausting all possible solution options. At this stage, it was decided to investigate whether alternative systems supplied by other vendors (i.e. vendors $B$ and $C$ ), who are not even part of the project's supply chain, could resolve the issues. An off-the-shelf product, supplied by vendor B, having mullions with standard length of 7 meters, was identified as a potential solution. This product would not also require the use of joints and/or reinforcement. This system was proposed to and accepted by the architects. However, this caused some further commercial issues. The alternative product, supplied by Vendor B - main competitor of vendor $A$ and not part of the project supply chain - required a sign-off from the central control office of the general contractor who has commercial exclusivity with Vendor A, whose approval was also needed. This process caused program delays as site curtain wall work package is on the critical path of getting the building weather proofed. In addition to the delays associated with this approval, the exploration of the engineering options discussed earlier result in time and cost related issues:

- The project's schedule was delayed by more than four weeks due to the additional design and research time spent on looking for alternative systems and in exhausting all possible options based on the preferred selected system. The additional spent time stretched also the available design resources, thus leading to delays in delivering the design of other parts of the building.

- The architects who were directly responsible to the main client for quality control had to be fully and formally convinced and informed that the original system could not be used. This was a time consuming process that meant reissue of drawings and technical data showing and justifying the issues encountered.

- The new system identified had to be submitted for approval. This included the issue of samples from a new supplier, drawings, technical data and warranties that eventually needed to be issued to the client for approval.

Together these consequences, resulting from the inaccurate selection of the building facade element, represented a significant wastage of resources and caused time and cost overruns for all the stakeholders involved (i.e. architect, client, contractor, suppliers, specialist building facade contractor and structural consultant).

\section{The current business process for selecting building facade elements}

The retrospective case study revealed some issues related to the early selection of building enveloped elements of such curtain wall systems. Using the results from the retrospective case study and the experience of the project manager - case study storyteller - who has thirty years of experience in managing building facade projects, this section depicts the current business process used to select curtain wall systems in construction projects. This process will be verified with the results from the following industry survey. The selection decisions are represented in a business 


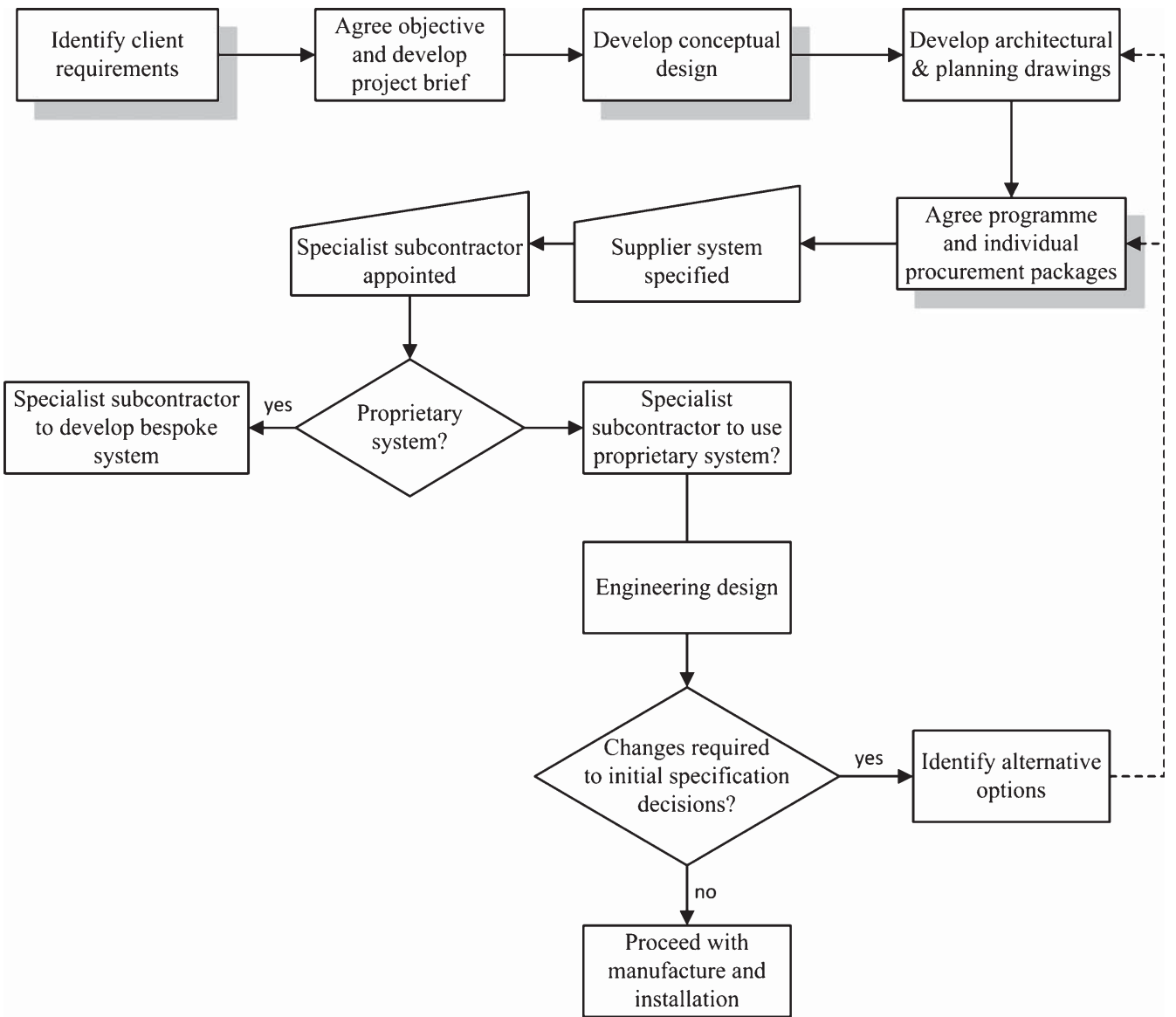

Fig. 3. Business process adopted for the selection of curtain wall systems.

process which is defined as a set of coordinated tasks and activities to achieve a project objective (Kassem et al., 2011). The current business process, reflecting current practices, is depicted in Figure 3. It shows the key of the issue of the late appointment and involvement of building facade specialist consultants and subcontractors, which is currently made after the selection decisions have been made at the early and design phases. It is known that design decisions have the biggest impact on the project lifecycle phases and building performance (Schade et al., 2011) and incorrect design decisions bring adverse impact on project participants and are responsible for many of the construction failures (Andi \& Minato, 2003). Rework, which is often experienced in construction projects, is regularly attributed to errors made during the design process (Love et al., 2000). These statements were proven in the case study earlier. Together, the delayed involvement of facade consultant and subcontractor specialists and the limitations of off-the-shelf building facade elements were very detrimental to projects as evidenced in the retrospective case study. The early opportunity to build for greater flexibility and give broader scope in the selection of building facade elements is missed in current business processes. Figure 3 shows the three entry points (shaded boxes) at which facade consultants and/or specialist subcontractors could be involved to overcome such issues in a proactive manner. A further validation of this business process and a comprehen- 
sive overview of the issues depicting current selection business processes will be the subject of the industry survey.

\section{Industry survey}

The results of the case study cannot be generalised to all projects or to the whole sector. An industry survey, followed by face to face and phone interviews with industry experts, was used for explorative purposes to obtain a thorough understanding of the issues associated with selection and specification decisions of building facade elements. Two criteria in sampling participants and conducting the survey aimed to respectively increase the internal and the external validity of findings. The first criterion is that all participants must be actively involved in or are stakeholders who can influence the early selection of curtain wall systems. The second criterion is that the sample size must allow the findings to be generalised at sector level. To meet the sampling criteria, participants were selected from renowned and leading architectural, consultancy and contracting organizations and only included in the sample if they were actively involved in large commercial and residential construction projects where curtain wall systems are mostly used as main elements of building facades. According to these sampling criteria, sixty individuals were preselected with the support of two project managers who had more than twenty years of experience in the sector. 54 participants expressed interest in taking part and commitment to give information and came from organisations operating at European and international scale such as Laing O'Rourke, Mace, Balfour Beatty, Morgan Ashurst, Bovis Lend Lease, Bennett's Architects, CWA Architects, Axis Mason Architects, RMA Architects, Galliford Try, Barr Construction, Dandara, and Berkeley First. Both semi-structured questionnaires followed by either a face to face dialogue or telephone interview were used in the industry survey. To increase further the internal validity of the survey, two actions were undertaken. First, a pilot questionnaire was tested with an operation director who had thirty years of experience in the facade industry. This ensured that the questions in the survey were perceived as both clear and relevant. Second, the telephones and face to face interviews were used with most participants to gather more information about the open-ended statements given by the participants.

To adequately answer the issues researched, the questionnaire was organised into three sections having distinct objectives:

- Awareness of stakeholders about commercially available curtain wall systems.

- Knowledge of stakeholders about the engineering and technical performance of commercially available curtain wall systems that affect selection decision.

- Value of available product selection guidance offered by vendors.

The commercially available facade systems considered in the questionnaire, and supplied by the vendors, denoted as vendor $A$, vendor $B$ and vendor $C$, could be generalised to the entire UK and EU market as the three companies together have more than $70 \%$ of the European market. This was verified in the case of the UK with actual figures from the Companies House - executive agency of the Department for Business Innovation and Skills - and the three vendors considered in this study had just more than $70 \%$ of the UK market valued at $\$ 250$ million in 2008 (Companies House 2008 tax returns).

The questions asked under each section and answers obtained are respectively summarised in Tables 4,5 and 6 respectively. 
Table 4

Awareness of stakeholders about available curtain wall systems

\begin{tabular}{|c|c|c|c|c|c|c|}
\hline \multicolumn{7}{|c|}{ how well you know the facade and curtain wall industry? } \\
\hline \multicolumn{2}{|c|}{ very well $(8 \%)$} & quite well (70\%) & \multicolumn{2}{|c|}{ not very well (11\%) } & \multicolumn{2}{|c|}{ not at all(11\%) } \\
\hline \multicolumn{7}{|c|}{ do you employ a facade consultant? } \\
\hline \multicolumn{2}{|c|}{ yes $(6 \%)$} & no $(65 \%)$ & \multicolumn{2}{|c|}{ occasional (11\%) } & \multicolumn{2}{|c|}{ never $(18 \%)$} \\
\hline \multicolumn{7}{|c|}{ how many curtain wall systems are you aware of? } \\
\hline \multicolumn{2}{|c|}{1 to $3(24 \%)$} & 3 to $6(41 \%)$ & \multicolumn{2}{|c|}{6 to $9(31 \%)$} & \multicolumn{2}{|c|}{ more than $10(4 \%)$} \\
\hline \multicolumn{7}{|c|}{ how many curtain wall systems have you had experience of working with? } \\
\hline \multicolumn{2}{|c|}{1 to $3(78 \%)$} & 3 to $6(17 \%)$ & \multicolumn{2}{|c|}{6 to $9(5 \%)$} & \multicolumn{2}{|c|}{ more than $10(0 \%)$} \\
\hline \multicolumn{7}{|c|}{ if asked to name major curtain wall systems used in the UK, which would you name? } \\
\hline \multicolumn{2}{|c|}{ system A $(54 \%)$} & \multicolumn{2}{|c|}{ system B $(42 \%)$} & & \multicolumn{2}{|c|}{ system C (4\%) } \\
\hline \multicolumn{7}{|c|}{ given the choice, which system would you prefer to work with? } \\
\hline \multicolumn{2}{|c|}{ system A $(48 \%)$} & \multicolumn{2}{|c|}{ system B $(39 \%)$} & \multicolumn{3}{|c|}{ system C (13\%) } \\
\hline \multicolumn{7}{|c|}{$\begin{array}{l}\text { does the company you work for have a specified system, i.e. the choice is already made due to } \\
\text { exclusivity deal with a particular supplier? }\end{array}$} \\
\hline \multicolumn{3}{|c|}{ yes $(6 \%)$} & \multicolumn{4}{|c|}{ no $(94 \%)$} \\
\hline \multicolumn{7}{|c|}{ what would be your main criteria for choosing a certain system? } \\
\hline $\begin{array}{c}\text { familiarity } \\
\text { and past } \\
\text { experience } \\
(23 \%)\end{array}$ & $\begin{array}{c}\text { cost } \\
(28 \%)\end{array}$ & $\begin{array}{l}\text { recommendation } \\
\quad(12 \%)\end{array}$ & $\begin{array}{l}\text { engineering } \\
\text { aspects }(12 \%)\end{array}$ & $\begin{array}{l}\text { aesthetic } \\
(17 \%)\end{array}$ & $\begin{array}{l}\text { technical } \\
\text { help }(8 \%)\end{array}$ & $\begin{array}{l}\text { lead } \\
\text { time } \\
(0 \%)\end{array}$ \\
\hline
\end{tabular}

\section{Findings and discussion}

The retrospective case study provided empirical evidence of the impact that inaccurate selection and specification of building facade elements can have on the program's schedule and costs. The identified issues and challenges are causing time and cost overruns in construction projects in the form of: time for re-producing new drawings or amend existing drawings, suspension of construction works, submission of new planning permissions, delays in procurement and fabrication due to new lead times, and in some cases, commercial issues, when there were exclusivity deals. This is very detrimental, not only to the building facade work package, but to the entire project, as in all construction projects curtain wall completion is always on the critical path for getting the building weather-proof. The case study introduced also some of the preliminary issues causing such a negative impact. The results of the survey provide further evidence by showing that cases where curtain wall systems, specified 
Table 5

Knowledge of stakeholders about the engineering and technical performance

\begin{tabular}{|c|c|c|c|}
\hline \multicolumn{4}{|c|}{$\begin{array}{l}\text { when selecting a curtain wall systems at the concept design stage, how confident are you that it will } \\
\text { meet the engineering requirements (i.e. accommodate the building movement, deflections and } \\
\text { imposed loads etc.)? }\end{array}$} \\
\hline not confident $(15 \%)$ & fairly confident $(15 \%)$ & confident $(61 \%)$ & very confident $(9 \%)$ \\
\hline \multicolumn{4}{|c|}{$\begin{array}{l}\text { who would you rely on to confirm that the system will meet the project needs in terms of engineering } \\
\text { capabilities? }\end{array}$} \\
\hline $\begin{array}{c}\text { specialist } \\
\text { subcontractor }(54 \%)\end{array}$ & own knowledge (31\%) & system vendor $(15 \%)$ & facade consultant $(0 \%)$ \\
\hline \multicolumn{4}{|c|}{$\begin{array}{l}\text { have you ever had experience of the specified envelope elements being changed due to their } \\
\text { incapability of meeting engineering and technical requirements? }\end{array}$} \\
\hline never $(67 \%)$ & \multicolumn{2}{|c|}{ sometimes $(33 \%)$} & often $(0 \%)$ \\
\hline \multicolumn{4}{|c|}{ do you think you are given enough information upfront - before system selection and specification? } \\
\hline \multicolumn{2}{|c|}{ yes $(31 \%)$} & \multicolumn{2}{|c|}{ no $(69 \%)$} \\
\hline \multicolumn{4}{|c|}{ is the information required in question 12 readily available from suppliers? } \\
\hline \multicolumn{2}{|c|}{ yes $(37 \%)$} & \multicolumn{2}{|c|}{ no $(63 \%)$} \\
\hline \multicolumn{4}{|c|}{$\begin{array}{l}\text { do you think there is a difference in the amount of building movement that can be accommodated } \\
\text { between different system supplier's products? }\end{array}$} \\
\hline yes $(18 \%)$ & & $15 \%)$ & not sure $(67 \%)$ \\
\hline
\end{tabular}

Table 6

Value of available product selection guidance offered by vendors

\begin{tabular}{|c|c|c|c|c|}
\hline \multirow{2}{*}{ Q. 15} & \multicolumn{4}{|c|}{ are you aware of any specifier guidance documentation/technical notes? } \\
\hline & British standard ( $8 \%)$ & trade bodies $(8 \%)$ & CWCT $(31 \%)$ & others $(11 \%)$ \\
\hline \multirow{2}{*}{ Q. 16} & \multicolumn{4}{|c|}{ do these technical notes/guidance information give any specific system advice? } \\
\hline & yes $(8 \%)$ & & & sure (20\%) \\
\hline
\end{tabular}

at the early design stage, had to be changed later on in the project due to their inability to meet engineering requirements are not unusual (question 11). On the one hand, this is partly caused by the limited knowledge of the stakeholder, involved in the early specification, of engineering performance of curtain wall systems (questions 1, 9 and 14). Similar findings were identified in other studies, where a survey of architects ranked the 'lack of in-house expertise' and 'lack of industry expertise' as major limitations at the design stage (Jaillon \& Poon, 2010). On the other hand, the appointment of specialist facade consultants and subcontractors is often left until late in the business process as evidenced in the mapping of the business process (Fig. 3) once the opportunity of influencing specification decisions and their impact is already missed. This was also confirmed in the survey, where more than $65 \%$ of participants acknowledged that they do not appoint a facade consultant (question 2 ). 
In follow-up telephone interviews, only three participants confirmed that they generally employ a facade consultant to support the selection of the facade system. Interviewees explained that in the majority of cases consultants are only called in to investigate and solve unforeseen problems after they occurred at the construction phase. Most interviewees justified this practice on a cost cutting ground and indicated that they do not deem this initial cost value for money.

Facade consultants were generally seen as a 'necessary evil' - as expressed by one participant once problems had become apparent. Facade consultants are either hired later once the issues have occurred or not appointed at all as occurred in the retrospective case study. Also, in common with the retrospective case study where an exclusivity deal existed between the main contractor and curtain wall system vendors, the survey showed that in some cases (6\%) there are commercial influences such as an inclusivity deal between the contractor and the curtain wall vendor (question 7). Participants interviewed confirmed that in those cases, the specification options for architects and consultants are even further restricted and technical issues could become unavoidable in those cases. One specialist subcontractor stated: "We have the most to gain if the right system is selected and we can ensure that the right system is selected. However, we have very little opportunity to influence the decision due to our usual late appointment".

The availability of information from curtain wall vendors is inadequate and difficult to obtain (questions 12 and 13). Early specifiers are aware of just a limited number of curtain wall systems and usually adopt the system they know best until a problem arises (questions 3 and 4) or "specify the systems of those suppliers that appear to offer the most secure warranties and technical assistance", noted one of the participants.

The limited awareness of participants of available curtain wall systems can have significant commercial implications on the market share. Vendors with the highest marketing budget and capabilities could have their systems specified on more and more projects and their market share could grow increasingly.

Merging together four of the survey findings (i.e. 1. limited knowledge of stakeholders of engineering performance, 2. technical guidance and information are either unavailable or not user-friendly, 3. the non-appointment of facade consultant and 4. the late appointment of facade subcontractor) gives indications of the root-causes of the challenges and risks affecting the selection process in this considerable and expensive industry. If the four issues are seen as constraints in the current industry business processes, a solution that concurrently addresses them is to bring forward engineering information of building facade elements to the early specification phase in a simplified and integrated manner - to cover all commercially available systems - simplistic and user friendly format - to match the limited knowledge of stakeholders.

The first contribution of this research was to provide the empirical evidence, by illustrating a real case study and an industry survey of the major players, of the challenges affecting the selection of facade systems at the early design phase, and to identify the root causes of issues creating wastage in the building facade sector. Indeed, together the case study and the industry survey depicted a holistic identification and explanation of both the issues and their implications. The findings from both the case study and industry survey can be used to classify the issues into four distinct categories:

- Limited understanding by the decision makers, involved in the early specification, of the engineering and technical parameters of facade systems.

- Tendency or reluctance to appoint specialist consultants and subcontractors early in the business process. 
- Lack of tools or methodologies that provide information in a user friendly and simplistic format that match the level of experience of the early decision makers, and

- Commercial influences that affect the early specification and restrict the available selection options.

Research and development efforts that aim to address the identified issues need to distinguish between the issues that are rooted in the industry mindset and those that are purely related to technical issues. The latter can be addressed in the short and mid-term compared to the former that require a long-term cultural change. Indeed, as noted by three participants in the follow-up interviews, some of the identified issues, such as the delayed appointment of specialist contractors and the reluctance to appoint consultants, are rooted in the construction industry and could persist in the short and mid-term, despite several studies researching and invoking the need for early stakeholder involvement. For example, studies focusing on the importance of early stakeholder involvement (Wikstrom et al., 2010; Kagioglou et al., 2000) and interaction (Tribelsky \& Sacks, 2011) and their impact on value creation (Mitropoulos \& Howell, 2002) have proliferated since more than one decade and was emphasized in a notable industry report (i.e. Egan Report (1994) - Rethinking Construction). However, issues related to the lack of involving stakeholders at suitable decision points in construction projects are still occurring, as this case study and survey have demonstrated. Early stakeholder involvement gives projects the opportunity to utilize and exploit a richer knowledge base (Ramaswamy \& Gouillart, 2010). In the case of building facade, as it was demonstrated in the case study and the survey, the specialist knowledge of building facade consultants and specialist subcontractors is not exploited due to their late or non-involvement.

A recent study, investigating the state of integration in the AEC community concluded that despite the acknowledged importance of integrated practices, integration levels vary among different disciplines (Uihlein, 2013). This study unraveled some of the collaboration issues specific to the building facade sector. In the short term, it is challenging to present solutions to rooted issues in the industry such as the culture of non-involving all relevant stakeholders in the early design phase. However, it is possible to address some technical issues, such as the lack of simple and user-friendly technical guidance, the complexity and fragmentation of guidance and the limited knowledge of stakeholders involved in early selection decisions. For example, a solution option is to facilitate specification and selection decisions by developing information management and decision support systems that bring forward engineering and technical information in a simplistic and user friendly manner to the stakeholders involved in the specification decisions (Kassem et al., 2012). This solution helps filling the knowledge gap of stakeholders and improves the communication and understanding of engineering performance at the early specification stage.

Very few studies, aimed at addressing the aforementioned issues with the specific focus on the facade industry, are available. Chin et al. (2004) and Hwang et al. (2006) presented a conceptual framework with three dimensions: production management, organization management, and information management. The production management dimension aims at clarifying the performance requirements for curtain wall and reducing design reworks through manufacturability and constructability reviews. The organization management dimension tackles the nontechnical issues such as the need to change owner's and architect's attitude, and the need for improving contractual arrangement. Finally, the information management dimension consists of an 'alternative information-based solution' for each of the reported issues. However, subsequent papers published by the authors (e.g. Hwang et al., 2006) have focused only on the processes downstream the design stage (i.e. manufacturing, delivery 
and installation) and therefore, did not address the specification decisions at the early design phases. Also their framework made no distinction between off-the-shelf and bespoke curtain wall systems. The retrospective case study and survey showed that the use of off-the-shelf systems are a popular choice on projects and due to the limitations of such systems, issues arise in design and construction phases. A proposed decision support system to aid the selection process of off-the-shelf curtain wall systems was developed for the products of three major vendors (Kassem et al., 2012). The system enables users to identify products that meet the project and engineering requirements. However, the development of the proposed system revealed further challenges. One major challenge consisted of the need for a taxonomy that can to be adopted across all vendors' systems to uniquely represent key technical parameters between vendors' systems. Resolving the taxonomy challenge in the representation of engineering parameters and performance of building facade products across different supplies will facilitate information management systems and consequently increase the sharing of information between stakeholders. This will also contribute to unravelling some of the less known building facade systems to the stakeholders involved in selection decisions.

The final contribution and implication of this research is to instigate or complement methodological approaches in the subject area of 'investigating and identifying issues affecting construction projects' with a new approach in which the granularity and scale of investigation is increased to project and disciplinary level (i.e. building facade), without overlooking the link with other disciplines (i.e. architectural and structural). As evidenced from this research, this approach proved to be effective in identifying the very nature of issues and their root causes.

\section{Conclusions}

The overarching aim of this research was to empirically identify the issues and challenges affecting the selection of building facade at the early design, the impact of their specification decisions on construction projects, and potential solutions. The use of the retrospective case study, process mapping and the industry survey helped to achieve this aim. The case study systematically demonstrated some of the issues affecting the early selection and building facade elements and their impact. The lack of involvement of facade consultants and specialist facade sub-contractors results in selection of building facade systems that do not meet the project and engineering requirements. Such issues, revealed only at the late construction phase, have adversarial effects not only on the project's schedule and cost but also on the commercial relationships between stakeholders in some circumstances. The industry survey contributed to identify an exhaustive list of the issues affecting the business process of building facade selection and the root cause of such issues. The root cause of issues were classified into four categories, namely: limited understanding of engineering parameters by stakeholders involved in the early selection, reluctance in the appointment of specialist consultants and subcontractors at early stages of the procurement process, lack of tools or methodologies that provide information in a user friendly way to match the limited technical knowledge of stakeholders, and commercial constraints such as exclusivity deals that restricts the options available.

In addition to filling the research gap in literature, this study adopted and instigated a new methodological approach in this research domain. The approach chosen consisted of increasing the granularity of investigation by focusing on a specific building trade and providing empirical evidence of the issues and their impacts. This will warrant an incisive inquiry into the very nature of issues affecting the subject investigated. In such a context, this research instigates: 
- Domain researchers, who are interested either in exploring issues (time, cost or quality related) in construction projects in general or in understanding how to bridge the gap between early design decisions and engineering implications, to increase the depth of investigation from sector-wide level to a more granular level such as a single building trade.

- Industry players to develop methodologies and systems that bring forward engineering information in a simplistic and user-friendly manner to all the stakeholders involved in the selection process.

- Researchers and industry players to build a taxonomy of technical terms and concepts across all facade systems' vendors to facilitate the comparison of engineering performance at the early design process in a systematic manner.

\section{References}

Al-Hajj, A., \& Hamani, K. (2011). Material Waste in the UAE Construction Industry: Main Causes and Minimization Practices. Architectural Engineering and Design Management, 7(4), 221-235.

Amaratunga, A., Baldry, D., Sarshar, M., \& Newton, R. (2002). Quantitative and qualitative research in the built environment: Application of "mixed" research approach. Work Study, 51(1), 17-31.

Andi, A., \& Minato, T. (2003). Design documents quality in the Japanese construction industry: Factors influencing and impacts on construction process. International Journal of Project Management, 21(7), 537-546.

Assaf, S. A., \& Al-Hejji, S. (2006). Causes of delay in large construction projects. International Journal of Project Management, $24,349-357$.

Chin, S., Yoon, S. W., Kim, C. D., Choi, Y. K., \& Chun, J. Y. (2004). An analysis of the life-cycle curtain wall process through supply chain management. Proceedings of International Group of Lean Construction, IGLC 12. Copenhagen, Denmark, 2004.

CWCT (Centre for Window and Cladding Technology) (1999). Introduction to structural design of stick curtain walling. CWCT Technical Note, No. 26.

CWCT (2000a). Cladding types. CWCT Technical Note, No. 14.

CWCT (2000b). Weather tightness and drainage. CWCT Technical Note, No. 17.

CWCT (2000c). Introduction to wind loading on cladding. CWCT Technical Note, No. 2.

CWCT (2003). Introduction to building envelope acoustics. CWCT Technical Note, No. 37.

CWCT (2007). Movement accommodation in building envelope. CWCT Technical Note, No. 55.

CWCT (2011). Fire performance of curtain walls and rain screen. CWCT Technical Note No. 73.

Eastman, C., Teicholz, P., Sacks, R., \& Liston, K. (2011). BIM Handbook: A Guide to Building Information Modeling for Owners, Managers, Designers, Engineers and Contractors, 2nd Ed. New Jersey, NY: John Wiley \& Sons, Inc.

Efstathiades, C., Baniotopoulos, C. C., Nazarko, P., Ziemianski, L., \& Stavroulakis, G. E. (2007). Application of neural networks for the structural health monitoring in curtain-wall systems. Engineering Structures, 29(12), 3475-3484.

El-Razek, M. E. A., Bassioni, H. A., \& Mobarak, A. M. (2008). Causes of delay in building construction projects in Egypt. Journal of Construction Engineering and Management, 134, 831-841.

Fallahnejad, M. H. (2013). Delay causes in Iran gas pipeline projects. International Journal of Project Management, 31(1), $136-146$.

Hwang, D. W., Choi, S. W., Song, Y. W., \& Choi, Y. K. (2006). Information exchange of curtain wall work for the application of supply chain management system. Proceedings of the 23rd International Symposium on Automation and Robotics in Construction, (ISARC), Tokyo, Japan, 2006.

Jaillon, L., \& Poon, P. S. (2010). Design issues of using prefabrication in Hong Kong building construction. Construction Management and Economics, 28(10), 1025-1042.

Jin, Q., \& Overend, M. (2010). A thermal performance analysis model for the design optimisation of high performance glazed facades. Engineered transparency. International Conference at Glasstec, Düsseldorf, Germany, 2010.

Kagioglou, M., Cooper, R., Aouad, G., \& Sexton, M. (2000). Rethinking construction: The generic design and construction process protocol. Engineering. Construction and Architectural Management, 7(2), 141-153.

Kassem, M., Dawood, N., \& Mitchell, D. (2011). A structured methodology for enterprise modeling: A case study for modeling the operation of a british organization. Journal of Information Technology in Construction, 16, 677-690.

Kassem, M., Dawood, N., \& Mitchel, D. (2012). A decision support system for the selection of curtain wall systems at the design development stage. Construction Management and Economics, 30(12), 1039-1053.

Kragh, M. (2011a). Façade Engineering and the design team of the future. Society of Façade Engineering. Executive Boardroom Commentary, 30-36. Retrieved from http://www.cibse.org/getmedia/28be6591-0d43-429e-a14c-8c64c7ecb315/kragh-paper.pdf.aspx 
Kragh, M. (2011b). The decade of the façade engineer. Society of Façade Engineering. Intelligent Glass Solutions, 1, 44-51. Retrieved from http://www.cibse.org/getmedia/eb0a8348-e754-4e78-bd7e-c8674e861d91/kragh-4.pdf.aspx

Love, P. E. D., Mandal, P., Smith, J., \& Li, H. (2000). Modelling the dynamics of design error induced reworking construction. Construction Management and Economics, 18(5), 567-574.

Mitropoulos, P., \& Howell, G. A. (2002). Renovation projects: Design process problems and improvement mechanisms. Journal of Management in Engineering, 18(4), 179-185.

Mohsen, F., \& Elaheh, N. (2012) Building envelope as an environmental apparatus: Integrating architectural and natural systems. ICSDEC, 2012, 268-275.

Odeh, A. M., \& Battaineh, H.T. (2002). Causes of construction delay: Traditional contracts. International Journal of Project Management, 20, 67-73.

Pavitt, T., \& Gibb, A. (2003). Interface management within construction: In particular, building façade. Journal of Construction Engineering and Management, 129(1), 8-15.

Quirouette, R. (2013). Glass \& Aluminium Curtain Wall Systems, Ontario Association of Architects.

Ramaswamy, V., \& Gouillart, F. (2010). The power of co-creation: Build it with them to boost growth, productivity and profits. New York, NY: Free Press.

Rossman, G. B., \& Wilson B. L. (1991). Number and words revisited: Being 'shamelessly eclectic'. Evaluation Review, 9(5), 627-643.

Schade, J., Olofsson, T., \& Schreyer, M. (2011). Decision making in a model-based design process. Construction Management and Economics, 29(4), 371-382.

Shebob, A., Dawood, N., Shah, R. K., \& Xu, Q. (2012). Comparative study of delay factors in Libyan and the UK construction industry. Engineering Construction and Architectural Management, 19(6), 688-712.

Singhaputtangkul, N., Low, S. P., Teo, A. L., \& Hwang, B. G. (2014). Criteria for architects and engineers to achieve sustainability and buildability in building envelope designs. Journal of Management in Engineering, 30(2), 236-245.

Succar, B., \& Kassem, M. (2015). Macro-BIM adoption: Conceptual structures, Automation in Construction, 57, September 2015, 64-79.

Sun, M., \& Meng, X. (2009). Taxonomy for change causes and effects in construction projects. International Journal of Project Management, $27(6), 560-572$.

Sweis, G., Sweis, R., Hammad, A. A., \& Shboul, A. (2008). Delays in construction projects: The case of Jordan. International Journal of Project Management, 26, 665-674.

Tran, D., Behr, R., \& Parfitt, M. (2014). Global differences in building enclosures, Journal of Architectural Engineering. http://dx.doi.org/10.1061/(ASCE)AE.1943-5568.0000146

Tribelsky, E., \& Sacks, R. (2011). An empirical study of information flows in multidisciplinary civil engineering design teams using lean measures. Architectural Engineering and Design Management, 7(2), 85-101.

Tumi, S. A. H., Omran, A., \& Pakir, A. H. K. (2009) Causes of delay in construction industry in Libya. In: Proceedings of the International Conference on Economics and Administration (pp. 265-272).

Uihlein, M. (2013). State of integration: Investigation of integration in the A/E/C community, Journal of Architectural Engineering. http://dx.doi.org/10.1061/(ASCE)AE.1943-5568.0000139

Vigener, N., \& Brown, M. (2012). Building Envelope Design Guide-Curtain Walls. Washington, DC: National Institute of Building Sciences.

Wikstrom, K., Artto, K., Kujala, J., \& Soderlund, J. (2010). Business models in project business. International Journal of Project Management, 28(8), 832-841.

Yin, R. B. (1994). Case Study Research: Design and Methods (2nd ed). Thousand Oaks, CA: Sage Publications.

Zoya Kpamma, E., \& Adjei-Kumi, T. (2011). Management of waste in the building design process: The Ghanaian consultants' perspective. Architectural Engineering and Design Management, 7(2), 102-112. 